\title{
La formació inicial i el caràcter dels mestres
}

\section{Francisco Esteban Bara*}

Recepció original: 23 de setembre de 2019

Acceptació: 10 d'octubre de 2019

Publicació: 20 de gener de 2020

Qualsevol persona que estigui mínimament interessada en l'educació pot sospitar que el caràcter dels mestres és un tema important. Certament, si del que es tracta és d'ensenyar quelcom a un grup d'alumnes, no serà suficient amb dominar un grapat de continguts o mostrar-se competent en un conjunt de competències psicopedagògiques. Sens dubte que tot això és important, però no és suficient. Volem pensar que darrera d'un contingut que ha de ser transmès hi ha una persona que l'explica, i per tant, una individualitat que li posa veu i rostre; sí, al món de l'educació es pot dir que les matemàtiques, la història, les ciències naturals, la llengua i la literatura, sigui el que sigui, són qüestions emparaulades i encarnades. I de la mateixa manera, considerem que darrera la metodologia psicopedagògica de torn i la innovació didàctica del moment hi ha una persona que l'estudia, l'analitza, la posa per obra; algú que no oblida que, per damunt de la tècnica hi ha humanitat, persones que estan creixent en el sentit més profund de les paraules.

Molt abans, emperò, els grans educadors com ara Plató i Aristòtil també es van preocupar a l'Acadèmia i al Liceu - dos gimnasos que van esdevenir institucions ateneses emblemàtiques - per assenyalar el camí de la veritat, ja fos en el món eidètic o bé en el realisme inductiu. Lògicament, la ciència medieval va recuperar aquesta doble tradició — platònica i aristotèlica — que va ser cristianitzada a través de sant Agustí i sant Tomàs i que va donar lloc al sorgiment de les universitats que, durant l'època moderna, van viure d'esquena a les aportacions de la ciència moderna (Descartes, Galileu, Kepler, etc.). Com és ben sabut, les coses van canviar a partir del segle XIX quan van aparèixer disciplines com la química, la pedagogia i la sociologia, de manera que les universitats van ser receptives a les aportacions científiques amb l'organització de seminaris per al cultiu de les humanitats i de laboratoris per al tractament de les ciències experimentals.

Ara bé, hem de dir que això no succeeix tant com ens agradaria. El món de l'educació, especialment en els darrers anys, inclou polítiques, discursos teòrics i propostes pràctiques on el caràcter dels mestres passa desapercebut, per damunt: gairebé no es contempla. Allò que era tan important per la filosofia educativa clàssica i que es podria dir que s'arrela a la crítica de Sòcrates als sofistes, s'està apagant a poc a poc. Potser és que no ens acabem de creure que la manera de ser del professorat converteix l'educació en un fet meravellós, fins i tot misteriós:

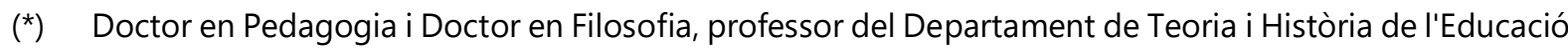
de la Universitat de Barcelona (UB) i membre del grup consolidat de Recerca en Educació Moral (GREM). Les seves investigacions estan centrades en la formació del caràcter dels mestres i la filosofia de la formació universitària, àmbits sobre els quals té diverses publicacions internacionals. Adreça electrònica: franciscoesteban@ub.edu 
El Dr. Piken era un exemple típic del procés d'osmosi pel qual es transmet una herència cultural i intel·lectual [...]. La seva actitud cap a l'aprenentatge era l'extrem oposat de la que ha arribat a ferse dominant a les nostres escoles i universitats actuals. No creia que el propòsit del coneixement fos ajudar a l'estudiant. Tot el contrari. Per ell, el Dr. Piken, el propòsit de l'estudiant és contribuir al coneixement ${ }^{1}$.

Aquest monogràfic pretén aprofundir en aquest tema del caràcter dels mestres i la seva potencialitat, o si es prefereix, vol apostar pel caràcter dels mestres per tal de disposar d'una educació de qualitat. I, d'entrada, volem agrair a Temps d'Educació I'aposta valenta i decidida que fa per aquest assumpte. Aquesta revista universitària no només demostra valentia, també un acurat sentit de situar-se a alçada de les circumstàncies, doncs camina de la mà dels més reconeguts journals internacionals en educació i filosofia educativa que ja estan dedicant monogràfics a aquest tema. Els diferents autors i autores d'aquest monogràfic, i qui signa aquestes paraules, se senten gratificats i joiosos per disposar d'aquest espai als nostres temps, i més encara, si és Temps d'Educació.

El primer treball està signat pel professor Jordi Garcia Farrero i les professores Begoña Román i Isabel Vilafranca. Es tracta d'un interessant treball que demostra que la formació del professorat ha estat una invariant pedagògica de l'era contemporània, especialment des de la Gran Guerra fins als nostres dies. I si s'ha identificat aquesta invariant és perquè s'han trobat raons de pes, motius substancials, fites d'alçada. Avui dia assumim que la formació inicial de mestres és quelcom obvi, una qüestió que no cal justificar massa. No obstant això, aquesta obvietat no ens pot deixar tranquils, especialment perquè estem vivint un temps on les obvietats s'han de justificar més que mai. Aquest treball ens ajuda a això precisament, a trobar raons fortes i compromeses per al nostre discurs educatiu, o si es prefereix, a fer-nos forts davant d'aquelles persones que ens interroguen $\mathrm{i}$ no troben raons històriques per justificar d'on venim i cap a on podríem anar.

El segon treball d'aquest monogràfic continua amb aquesta línia filosòfica i educativa. Segons com es miri, podria ser un complement del primer. Una vegada s'ha presentat la necessitat de la formació inicial de mestres com a invariant a la nostra cultura educativa, ara toca convidar una determinada formació. Com ja hem dit més amunt no apostem per qualsevol tipus de formació, només per aquelles que considerin la formació integral, és a dir, la formació del mestre i de la persona que ha de fer de mestre. Ser mestre no és qualsevol cosa, la professió d'ensenyar no es pot encarar de qualsevol manera. El caràcter d'un mestre, s'entén que d'un bon mestre, es nodreix de diversos ingredients i es fonamenta en diferents assumpcions. De tot això, és del que ens parla aquest treball signat pels professors Francisco Esteban Bara i Ferran Sánchez Margalef.

Els quatre treballs que venen a continuació se situen en el terreny pràctic, però sense perdre de vista les idees presentades als dos primers. I aquesta part pràctica, si es pot dir així, la comencem amb l'aportació del professor Josep Gustems i la professora Caterina Calderon. Venim parlant d'una bona mestra i una bona manera d'arribar a aquesta representació és a través de la psicologia positiva. Com és ben sabut, la psicologia positiva ha donat bons i curiosos resultats en molts i diversos àmbits, i certament, la formació de mestres també necessita ser mirada i analitzada

(1) Scuton, R., Bebo, luego existo. Madrid, Ediciones Rialp, 2017, p. 41. 
amb les seves ulleres. D'aquest article destaquem per damunt de tot les portes obertes que deixa a la reflexió i aplicació, els camins per obrir noves recerques i modes de pensar en el tema que ens ocupa, en les bones mestres.

El segon dels treballs de caire pràctic presentat pels professors Ernesto Colomo i Ángel Ignacio Aguilar és certament curiós i molt innovador. La figura del mestre i les seves maneres de ser també poden ser analitzades a partir del que es comenta a les xarxes socials virtuals. No descobrirem res si diem que aquestes xarxes tenen una gran incidència en l'imaginari social i col-lectiu; és més, inclús podríem dir que tenen un poder que ja gairebé no podem controlar. Una d'aquestes xarxes que té més incidència és Twitter i les infinites piulades (missatges curts) que emet dia a dia, minut a minut, segon a segon. La percepció social que es construeix dels mestres a través d'aquestes piulades és certament important, i ens diu, per una banda, cap a on van els trets en relació a la figura docent, i per altra banda, com podrien solucionar el tema, si és que aquells indrets als que sembla que ens dirigim no ens acaben de fer el pes.

El tercer treball de caire pràctic descriu un estudi empíric al que se'ls hi preguntava a estudiants de mestre com era per ells un bon mestre, i per què volien ser mestres. Sens dubte, són dues qüestions fonamentals aquestes que treballa el professor Teodor Mellen. Sorprèn que el caràcter dels mestres no és un ornament en les respostes rebudes, és més, sorprèn el pes que té en relació a altres aspectes i dimensions del professional de l'educació. Podríem dir inclús alguna cosa més: que les futures mestres no donen tanta importància a qüestions que avui sobrevalorem i que al mateix temps consideren molt rellevants aspectes que avui infravalorem. De la mateixa manera que als anteriors treballs, aquí també trobem pistes per seguir i portes per obrir; aquí també se'ns presenta que això de ser bon mestre no és tan fàcil com sembla ni tant evident com ens podem imaginar.

El quart i últim treball de caràcter pràctic, signat per les professores Maria Rosa Buxarrais i Amèlia Tey, presenta una recerca ben interessant. Es pot dir que Buxarrais i Tey s'endinsen en un tema que és molt important, i potser per aquesta raó, normalment passa desapercebut. Quan es parla del bon mestre es parla de moltes coses, de qüestions subjectives i objectives, i sota la majoria dels discursos que ja coneixem s'amaga una reflexió que no sempre veu la llum, una reflexió perenne que sempre està allà amagada i cridant el seu torn de paraula. La primera part del títol d'aquest treball representa molt bé allò que aquí es vol dir: la cara ètica del «bon mestre». Certament, un bon mestre pot ser moltes coses i es pot moure de moltes maneres, però sempre té una cara ètica, una mirada ètica, un somriure ètic. És molt recomanable aquest article per veure «algunes dades» de la fesomia d'aquesta cara tan important i tan rellevant, més encara avui dia.

En definitiva, estem davant d'un monogràfic que ens pot fer pensar i també ens pot ajudar a refrescar coneixements i idees a aquells que ja portem uns anys al món educatiu. Ara bé, potser és un monogràfic que pot ajudar a aquelles persones que estan fent un treball de recerca sobre el caràcter dels mestres, sigui una tesi, un Treball Final de Màster o qualsevol altre tipus d'indagació acadèmica. No és un monogràfic de solucions, és més aviat un monogràfic de preguntes obertes, i ens sembla que això és un bon senyal per a la formació inicial de mestres, i més concretament, per a la formació del seu caràcter. Ja sabem que en el món educatiu dos més 
dos no sempre són quatre, i que a vegades, trobem aquell quatre sense tenir-ho tot controlat sí, a vegades, és el caràcter d'una bona mestra el que converteix l'educació en un art, l'encontre educatiu en un fet inexplicable, i, per tant, meravellós. 